REVISTA DE DERECHO UNED, NÚM. 16, 2015

\title{
EL PAPEL DE LA INSPECCIÓN DE TRABAJO Y SEGURIDAD SOCIAL ANTE LA DISCRIMINACIÓN RETRIBUTIVA POR RAZÓN DE SEXO: UN ANÁLISIS A LA LUZ DEL PRINCIPIO DE TRANSPARENCIA
}

\section{THE ROLE OF LABOUR INSPECTION TO THE RETRIBUTIVE GENDER DISCRIMINATION: AN STUDY THROUGH TRANSPARENCY PRINCIPLE}

\begin{abstract}
SANDRA GARCÍA LOMBARDÍA
Inspectora de Trabajo y Seguridad Social. Ganadora del Premio Elisa Pérez Vera en su XVII edición. Alumna de posgrado de la UNED.
\end{abstract}

Resumen: El propósito del presente estudio es evaluar la persistencia de las causas de la brecha salarial en los Estados Miembros de la Unión Europea, a pesar de los esfuerzos realizados por ésta para la implementación del principio de igualdad retributiva. El análisis es realizado sobre la base del papel desempeñado por la Inspección de Trabajo, cuya experiencia en esta materia muestra la necesidad de adoptar medidas correctoras más eficaces en orden a combatir la discriminación retributiva basadas en la mejora de la transparencia de los sistemas retributivos.

Palabras clave: brecha salarial, Inspección de Trabajo, transparencia.

Abstract: The purpose of this study was to evaluate the persistence of the causes of gender pay gap in all the Member States of European Union, despite of the efforts to pursue the implementation of the equal pay principle. The analysis es made on the basis of the role played in this regard by Labour Inspection, whose experience 


\section{SANDRA GARCÍA LOMBARDÍA}

shows the need of implementing more effective corrective actions in order to combat pay discrimination, which may be based on improving transparency in pay sistems.

Key words: gender pay gap, labour inspection, transparency

Recepción original: 02/02/2015

Aceptación original: 27/02/2015

\section{INTRODUCCIÓN}

El estudio de las causas de la brecha salarial es una de las cuestiones abordadas de forma recurrente por la Comisión Europea, constituyendo una de sus acciones prioritarias ${ }^{1}$. En sus últimos informes sobre la transposición por los Estados miembros de la Directiva 2006/54/CE, relativa a la aplicación del principio de igualdad de oportunidades e igualdad de trato entre hombres y mujeres en asuntos de empleo y ocupación, la Comisión examina los factores que determinan la persistencia de la brecha salarial en todos los Estados miembros y las estrategias que sería necesario implementar para la aplicación efectiva del principio de igualdad retributiva, llegando a la conclusión de que «unas estructuras salariales opacas y la falta de información disponible sobre los niveles salariales de los trabajadores que realizan el mismo trabajo o un trabajo de igual valor son los principales factores que han contribuido a estas dificultades» para luchar contra la discriminación retributiva ${ }^{2}$, lo cual exige la introducción de políticas de transparencia en la composición y estructura salariales.

Interesa, por tanto, examinar en qué medida están presentes en nuestro ordenamiento laboral los problemas detectados por la Comisión Europea, ilustrando las consecuencias prácticas de los mismos. La aproximación a esta realidad práctica se realizará desde el estudio de la actuación del organismo administrativo al que compete la vigilancia del cumplimiento de las normas del orden social: la Inspección de Trabajo y Seguridad Social. La ausencia de estudios acerca del impacto del Derecho comunitaria antidiscriminatorio sobre la actua-

${ }^{1}$ Comunicación de la Comisión Bruselas, 5.3.2010 COM(2010)78 final, que recoge la Carta de la Mujer, disponible en https://www.msssi.gob.es/ssi/igualdadOportunidades/internacional/unioneuropea/CartadelasMujeres.pdf; y Punto 15 del Anexo del programa de trabajo para la Comisión para 2014, COM(2013) 739 final, disponible en: http://ec.europa.eu//atwork/pdf/cwp_2014_annex_es.pdf.

${ }^{2}$ Considerando n. ${ }^{\circ} 8$ de la Recomendación de la Comisión, de 7 de marzo de 2014, sobre el refuerzo del principio de igualdad de retribución entre hombres y mujeres a través de la transparencia, publicado en DOUE núm. 69, de 8 de marzo de 2014, páginas 112 a 116 . 
ción de la Inspección de Trabajo ha llamado la atención de la doctrina especializada ${ }^{3}$, sobre todo habida cuenta de la intensa actividad fiscalizadora planificada que este organismo ha desplegado en la última década en materia de discriminación por razón de género.

\section{LAS DIMENSIONES CONSTITUCIONALES DE LA IGUALDAD Y LA NO DISCRIMINACIÓN Y EL DERECHO DEL TRABAJO. CONEXIÓN CON EL PRINCIPIO DE TRANSVERSALIDAD DE GENERO}

La Constitución española no se limita a recoger una sola vertiente o faceta de la igualdad y la no discriminación, dándole carta de naturaleza en diversos preceptos, cada uno de ellos provisto de su propia significación, virtualidad y protección jurídica, dotándolo así de una eficacia pluridimensional: como valor superior del ordenamiento jurídico (artículo 1.1), como principio de igualdad formal, en la ley y ante la ley (artículo 14.1), como derecho a no ser discriminado por determinadas circunstancias personales o sociales, entre las que se cita expresamente el sexo (artículo 14.2) ${ }^{4}$ y finalmente, como princi-

\footnotetext{
${ }^{3}$ ESCANDE-VARNIOL, M. C.: Impacto y perspectivas del principio de igualdad de trato en los países de la Comunidad Europea. Informe de sintesis, Relaciones Laborales n. ${ }^{\circ}$ 8, Sección Crónica internacional y comunitaria, Quincena del 23 de abril al 8 de mayo, 2007, Año XXIII, pag. 1183, tomo 1, Editorial LA LEY.

${ }^{4}$ Doctrina y jurisprudencia han debatido en torno a la significación y autonomía del principio de no discriminación en relación con la clausula general de igualdad, dando lugar a dos posiciones básicas: la de quienes lo identifican como el perfil o dimensión negativa del principio de igualdad, y la de quienes lo configuran como un derecho autónomo. El TC inicialmente adopta la primera de la posturas, identificando el principio de no discriminación con una manifestación de la desigualdad desprovista de una justificación objetiva y razonable, con independencia de cuál haya sido el criterio de diferenciación empleado, ya sea uno de los expresamente enumerados en el artículo $14 \mathrm{u}$ otro diferente, si bien reforzando la tutela ante las diferencias en los supuestos expresamente proscritos (S. 22/1981, F. J. 3..$^{\circ}$ y 81/1982, F. J. 2. ${ }^{\circ}$ ). Sin embargo, la Sentencia 128/1987 marca el inicio de una nueva línea, que se ha llamado de «jurisprudencia compensadora», en la que el TC dota de significación autónoma al segundo inciso del artículo 14, como una explícita interdicción del mantenimiento de determinadas diferenciaciones históricamente muy arraigadas, que han colocado a determinados grupos y colectivos en una situación de preterición y desventaja abiertamente contraria a la dignidad de la persona que reconoce el artículo 10 de la CE ( SS. 166/1988, 90/1989, 49/1990, 145/1991, 229/1992 y 109/1993, entre otras). Esta postura va a tener, entre otros efectos, la esencial virtualidad de diferenciar el juicio de igualdad del juicio de no discriminación, ya que éste ultimo va a trascender del mero control de la razonabilidad de la diferencia de trato para exigir un plus: la paridad o mandato de parificación de dichos colectivos tradicionalmente desfavorecidos, conectando así con la dimensión material o real de la igualdad. Un estudio más detallado véase en SAEZ LARA, C.: Mujeres y mercado de trabajo, CES, Madrid, 1994, pp. 33 a 43; FERNANDEZ LOPEZ, M. ${ }^{a}$ F.: «La igualdad y la discrimi-
} 


\section{SANDRA GARCÍA LOMBARDÍA}

pio de igualdad material o de oportunidades, entendido como un mandato de optimización dirigido a los poderes públicos, en orden a la remoción de los obstáculos que impiden la igualdad efectiva de los colectivos y grupos afectados por dichas circunstancias.

En el seno del Derecho del Trabajo la igualdad va a desplegar toda su virtualidad jurídico-constitucional. En primer lugar, como valor, su eficacia axiológica va a tener, en palabras de RODRÍGUEZ-PIÑERO ${ }^{5}$, «un efecto multiplicador», en la medida en que todo el Derecho laboral es, histórica y teleológicamente, una expresión del principio de igualdad material. En efecto, el Derecho del Trabajo nace con una finalidad tuitiva y compensadora de la situación de desigualdad estructural inherente a la relación jurídico-laboral, desempeñando una función básica de realización de la justicia social y de pacificación de un sector de la vida social particularmente conflictivo. En este sentido, la justicia social se integraría por dos elementos ${ }^{6}$ : la igualdad de oportunidades de todos los individuos y la asunción por la sociedad organizada de la atención de aquellas necesidades vitales que determinados grupos de individuos no pueden atender satisfactoriamente por sí mismos.

El Derecho del Trabajo, por tanto, no limita su eficacia al principio de igualdad formal, sino que constituye uno de los ámbitos jurídicos donde de forma paradigmática se optimiza el principio de igualdad en su vertiente material o como igualdad de oportunidades.

Ambas dimensiones del principio de igualdad tienen, en materia de género, una plasmación especial en el llamado principio de trans-

nación en la jurisprudencia constitucional», en AAVV (M. R. Alarcón Caracuel, coord..) Constitución y Derecho del Trabajo: 1981, 1991 (Análisis de diez años de jurisprudencia constitucional, Marcial Pons, Barcelona, 1992, pp. 175 a 232.

En cuanto a la naturaleza jurídica del derecho a no ser discriminado por razón de sexo, la doctrina y la jurisprudencia constitucional vienen considerándolo un derecho fundamental. Vid., GIMENEZ GLUCK, D.: Una manifestación polémica del principio de igualdad: acciones positivas moderadas y medidas de discriminación inversa, Tirant lo Blanch, Valencia, 1999, p. 31; PEREZ LUÑO, A. E.: Dimensiones de la igualdad, Dykinson, Madrid, 2007, pp. 89 a 97; RODRÍGUEZ-PIÑERO, M.: Igualdad y no discriminación en el empleo, en Derecho y Conocimiento, vol. 1, p. 463; REY MARTINEZ, F.: El principio de igualdad y el derecho fundamental a no ser discriminado por razón de sexo, en Diario La Ley, 2000, D-27, tomo 1; NOGUEIRA GUASTAVINO, M.: El principio de igualdad y no discriminación en las relaciones laborales: perspectiva constitucional reciente, en Ian Harremanak/25 (2012), p. 19.

${ }^{5}$ RODRÍGUEZ-PIÑERO, M.: «El principio de igualdad y el Derecho del Trabajo», en El principio de igualdad en la Constitución española, Ministerio de Justicia, Secretaría General Técnica, Centro de Publicaciones, vol. II, Madrid, 1991, p. 1072.

${ }^{6}$ MARTÍN VALVERDE, A., RODRÍGUEZ-SAÑUDO GUTIÉRREZ, F. y GARCÍA MURCIA, J.: Derecho del Trabajo, Tecnos, Madrid, 2002, pp. 61 y 62. 


\section{El papel de la InsPección de Trabajo y Seguridad Social...}

versalidad o mainstreaming de género. La doctrina lo considera un subprincipio derivado del principio de igualdad ${ }^{7}$, tanto en su dimensión formal como material ${ }^{8}$. Este subprincipio goza de positivización legal, tanto a nivel comunitario (artículo 3.2 del Tratado de Amsterdam) como a nivel interno (artículos 14 y 15 de la Ley Orgánica 3/2007). El Grupo de expertos de la Unión Europea lo define como «la organización, mejora, desarrollo y la evaluación de los procesos políticos, de modo que una perspectiva de igualdad de género se incorpore en todas las políticas, a todos los niveles y en todas las etapas, por los actores normalmente involucrados en la adopción de medidas políticas $^{9} »$. LOUSADA AROCHENA ${ }^{10}$, en coherencia con la conexión del subprincipio con las dos dimensiones de la igualdad, distingue dos concepciones o vertientes en el contenido de la transversalidad de género: una formal, como instrumento de técnica jurídica dirigido a llevar e integrar en todo el ordenamiento jurídico el principio de igualdad entre hombres y mujeres; y una material o funcional, que obliga a una determinada forma de actuación de los poderes públicos tendente a acabar con la subordinación femenina. En este sentido, conlleva la necesidad de evaluar y revisar las propuestas y medidas legislativas, presentes y futuras, desde una perspectiva de igualdad de género. Precisamente, la vocación social del Derecho del Trabajo va a exigir que la dimensión material del principio juegue un papel fundamental en el desarrollo de la política legislativa laboral.

Partiendo de la perspectiva descrita, a continuación se analizará si la normativa laboral vigente contiene los mecanismos y herramientas necesarias para detectar y erradicar la discriminación retributiva, a fin de determinar si en qué medida se halla informada dicha normativa por ambas vertientes del principio de transversalidad. La aproximación a esta realidad práctica se realizará desde el estudio de la actuación del organismo administrativo al que compete la vigilancia del cumplimiento de las normas del orden social: la Inspección de Trabajo y Seguridad Social. La ausencia de estudios acerca del impacto del Derecho comunitaria antidiscriminatorio sobre la actuación de la Inspección de Trabajo ha llamado la atención de la doctrina especializada ${ }^{11}$, sobre todo habida cuenta de la intensa actividad fiscalizado-

${ }^{7}$ AAVV (CANCIO ÁLVAREZ, M. D. coord.), op. cit., pág. 78.

${ }^{8}$ LOUSADA AROCHENA, J. F.: El principio de transversalidad de la dimensión de género, MTAS, Madrid, 2007, pag. 36.

${ }^{9}$ AAVV (CANCIO ÁLVAREZ, M. D. coord.), op. cit., pág. 76.

${ }^{10}$ Op. cit., pp. 49 a 52.

${ }^{11}$ ESCANDE-VARNIOL, M. C.: Impacto y perspectivas del principio de igualdad de trato en los países de la Comunidad Europea. Informe de síntesis, Relaciones Laborales 
ra planificada que este organismo ha desplegado en la última década en materia de discriminación por razón de género.

\section{LAS COMPETENCIAS DE LA INSPECCIÓN DE TRABAJO EN MATERIA DE IGUALDAD DE GENERO}

La Inspección de Trabajo nace en el seno del Instituto de Reformas Sociales, creado en 1903 con la misión de «preparar la legislación de trabajo en su más amplio sentido, cuidando de su ejecución, organizando para ello los necesarios servicios de inspección...». Con fecha 1 de marzo de 1906 se aprueba el Reglamento de la Inspección de Trabajo, a la que se encomienda la vigilancia de la incipiente legislación laboral (integrada a la sazón apenas por tres leyes, la de accidentes de trabajo de 1900, la de trabajo de mujeres y menores de 1900 y la de descanso dominical de 1904), así como de «las demás leyes y disposiciones protectoras y reguladoras del trabajo dictadas o que puedan dictarse en lo sucesivo ${ }^{12}$. A partir de esta fecha, el desarrollo de la legislación laboral, preventiva y de Seguridad Social y la progresiva ampliación competencial del servicio de Inspección de Trabajo evolucionarían a la par, de una forma prácticamente mimética, dando lugar con el transcurso del tiempo al modelo actual, que constituye el «paradigma de modelo global» de sistema de Inspección de Trabajo, ya que su acervo competencial resulta tan amplio y completo que no encuentra prácticamente parangón en el resto de países de Europa, ni en los de inspiración nórdico-anglosajona ni en los de corte latino.

Ya en las primeras Instrucciones dictadas a los Inspectores de Trabajo para el régimen y unidad del servicio en 1909 se observa la primera muestra de interés por la proporción de salarios o jornales de hombres y mujeres. En el artículo 49 de estas Instrucciones se establece que «los Inspectores provinciales tendrán a su cargo la formación de la Estadística obrera de su respectiva provincia, y los Inspectores regionales la de sus regiones, sirviendo estas estadísticas para constituir el Censo de la población obrera en España», trabajo que los inspectores debían plasmar en las Hojas de Estadística (modelo n. ${ }^{\circ} 15$ de las Instrucciones), en las que debían desglosar por sexos («varones y hembras») la población obrera por edades y los jornales mínimo, medio y máximo percibidos por hombres y mujeres. Asimismo, de

\footnotetext{
n. ${ }^{\circ}$ 8, Sección Crónica internacional y comunitaria, Quincena del 23 de abril al 8 de mayo, 2007, Año XXIII, pág. 1183, tomo 1, Editorial LA LEY.

${ }_{12}$ Artículo 1 del Reglamento para el servicio de Inspección de Trabajo, publicado en la Gaceta de Madrid n. ${ }^{\circ}$ 63, de 4 de marzo de 1906.
} 
conformidad con el artículo 55, el Inspector debía ordenar «los datos, notas y observaciones» que resultasen de sus trabajos, para incluirlos en la Memoria anual. En esta línea, la primera Memoria anual del servicio de Inspección de Trabajo, de 1907, detallaba numerosos datos acerca de las diferencias existentes entre los jornales de hombres y mujeres. Estas primeras manifestaciones se hallan aún muy alejadas de la finalidad igualadora de salarios contemporánea, revistiendo un interés meramente estadístico, que pronto se tornaría también en «protector» de un salario femenino mínimo, tal y como se plasmó en la normativa posterior ${ }^{13}$.

Con la entrada en vigor de la Constitución de 1978 y el ingreso de España en la Unión Europea, el cumplimiento por parte de los empresarios a la prohibición de discriminación por razón de sexo en el ámbito laboral pasó a integrarse en los objetivos de vigilancia de la Inspección de Trabajo, tipificándose como infracción muy grave en el artículo 8.12 de la Ley 8/1988, de 7 de abril, sobre infracciones y sanciones en el orden social (BOE del 15), pasando al vigente texto refundido aprobado por Real Decreto Legislativo 5/2000 con algunas modificaciones.

La actuación de la Inspección de Trabajo y Seguridad Social en materia de igualdad por razón de género puede tener un origen rogado (como consecuencia de orden superior, petición razonada de otros órganos o de denuncia), de oficio, o como actividad planificada. Es precisamente esta última forma de actuación la que viene adquiriendo un notable protagonismo desde 2005 , fecha en la que comenzaron a aprobarse los sucesivos Planes de actuaciones de la ITSS para la vigilancia en las empresas de la igualdad efectiva entre mujeres y hombres (20052007, 2008-2010), en los que la Autoridad central (Dirección General de la ITSS) establece una programación anual de la actuación de las Inspecciones provinciales fijando un conjunto de objetivos, tanto en el plano cualitativo (áreas de actuación dentro de la materia) y cuantitativo (número de actuaciones a realizar), a partir de los cuales las Inspecciones provinciales dispondrán la programación interna de sus servicios, de conformidad con lo dispuesto en los artículos 28 y 31 del Real Decreto 138/2000, de 4 de febrero. La lucha contra la discriminación salarial no constituyó un área o campaña específica hasta la publi-

${ }^{13}$ Si bien la primera manifestación del principio de igualdad retributiva en nuestro país tuvo lugar con la Orden de 11 de diciembre de 1933, publicada en la Gaceta de 22 de diciembre, sobre igualdad de labores y de retribución para hombres y mujeres, esta norma tendría un escaso recorrido, debido al pronto estallido de la Guerra Civil. Mediante Orden de 3 de noviembre de 1938 se estableció por primera vez un salario mínimo provisional específicamente femenino. 
cación del Criterio Operativo 73/2009, sino que se integraba dentro del área genérica de vigilancia de la igualdad en las condiciones de trabajo. Esta iniciativa adquirirá relevancia normativa, al ordenar la disposición adicional $16 .^{a}$ de la Ley 35/2010, de 17 de septiembre, de medidas urgentes para la reforma del mercado de trabajo que la Inspección de Trabajo y Seguridad Social incluirá en su Plan Integrado de Actuación con carácter de objetivos de alcance general, la discriminación salarial entre mujeres y hombres como plan específico.

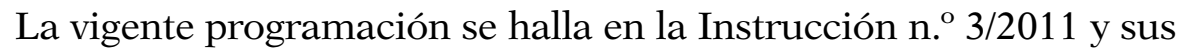
Anexos, que configura las actuaciones de la ITSS en materia de igualdad y no discriminación por razón de sexo como un área de actuación permanente en materia de Relaciones Laborales, de modo que junto a la actividad rogada se mantendrá de manera permanente una actividad programada, centrada en los ocho programas fijados en el anterior Plan de Actuaciones 2008-2010 (1. Planes de igualdad y otras obligaciones de la Ley de Igualdad; 2. Discriminación en la relación laboral; 3. Discriminación salarial; 4. Prevención de riesgos laborales con un enfoque de género; 5 . Acoso sexual y por razón de sexo; 6 . Discriminación en la negociación colectiva; 7. Discriminación en el acceso al empleo; 8. Derechos sobre conciliación de la vida familiar y laboral).

Entrando en el análisis de los Informes Anuales de Inspección de los últimos cuatro años y de los datos específicos que contienen en cuanto a los resultados de la actuación inspectora en esta área específica a nivel nacional, el de 2010 indica que se practicaron actuaciones de comprobación en materia de discriminación salarial en 362 empresas, iniciándose un procedimiento sancionador por esta causa. El de 2011 recoge que fueron 445 las empresas inspeccionadas, iniciándose asimismo un solo procedimiento sancionador. En 2012 fueron 411 las empresas inspeccionadas, y dos los procedimientos sancionadores incoados.

La discreción de los resultados de la actuación inspectora en esta materia debe conectarse causalmente con el origen de la misma: se trata de una actuación planificada, es decir, las empresas a inspeccionar se seleccionan en base a criterios abstractos (número de trabajadores, sector productivo al que pertenecen), sin que exista en realidad sospecha o indicio alguno de que en las mismas pueda estar produciéndose práctica discriminatoria alguna. La potenciación de esta actuación planificada o «en abstracto» obedece a la virtual inexistencia de denuncias por parte de trabajadores y sindicatos que, de algún modo, puedan orientar la acción inspectora hacia aquellos sectores o empresas en que realmente existan datos, prácticas o indicios que 
permitan presumir o sospechar una posible discriminación retributiva por razón de sexo. Se hace inexcusable por tanto, indagar sobre cuáles pueden ser las causas de la ausencia de denuncias en un ámbito en el que los datos estadísticos siguen arrojando la existencia de importantes diferencias salariales entre hombres y mujeres.

\section{Brecha salarial y discriminación retributiva}

La falta de denuncias, lejos de preconstituir una prueba de la ausencia de discriminaciones salariales, reviste más bien la condición de «síntoma» de la existencia de deficiencias en la estructura misma del ordenamiento jurídico-laboral que impiden la consecución efectiva de la igualdad salarial entre sexos. En efecto, todos los estudios estadísticos muestran que la brecha salarial entre hombres y mujeres, lejos de desaparecer o disminuir, persiste. La Encuesta de Estructura Salarial publicada por el INE en 2011 detecta una brecha salarial en España del $16.3 \%$ en ingresos brutos por hora trabajada entre hombres y mujeres, y del 22,99\% en términos de ganancia anual. La brecha salarial media en los Estados miembros de la UE se sitúa en el 16,2\%, según el Informe de la Comisión al Consejo y al Parlamento Europeo sobre la aplicación de la Directiva 2006/54/CE, emitido el 6 de diciembre de 2013. En este informe se identifican como causas de dicha brecha salarial, además de las discriminaciones retributivas directas o indirectas (pago de distinta retribución por la prestación de un trabajo de igual valor), la segmentación horizontal en el mercado de trabajo y la minusvaloración de los trabajos realizados primordial y tradicionalmente por mujeres (sectores feminizados) ${ }^{14}$, la alta segmentación vertical ${ }^{15}$ y problemas vinculados a roles tradicionales de

${ }^{14}$ Vid., CEBRIÁN, I. y MORENO, G.: La situación de las mujeres en el mercado de trabajo español: desajustes y retos, Revista de Economía Industrial n. ${ }^{\circ}$ 367, 2008, pp. 121-137. En este conocido estudio se pone de manifiesto como casi la mitad de las mujeres ocupadas en España se concentran en seis ocupaciones de baja cualificación.

${ }^{15}$ En 2013, las mujeres constituyeron solo el 17,8\% de los miembros de juntas directivas de las mayores empresas que cotizan en bolsa en el territorio de la UE y ocuparon únicamente el $4,8 \%$ de los puestos de dirección de dichas juntas. La proporción de mujeres en el cargo de consejero delegado fue todavía más baja, en un 2,8\%, (Base de datos de la Comisión Europea sobre las mujeres y los hombres en la toma de decisiones http://ec.europa.eu/justice/gender-equality/gender-decisionmaking/database/index_en.htm). A pesar de que las mujeres representan el $60 \%$ de los graduados universitarios en la UE, estos porcentajes no han sufrido variaciones significativas en los últimos años. 


\section{SANDRA GARCÍA LOMBARDÍA}

asunción de responsabilidades familiares y conciliación de vida familiar y laboral (que determina un altísimo porcentaje de parcialidad de jornada en el empleo femenino ${ }^{16}$ ).

La concurrencia de causas de muy variado origen e índole obliga a distinguir el concepto de desigualdad salarial entre mujeres y hombres, también llamado diferencia o brecha salarial, de la discriminación retributiva en sentido estricto. El concepto brecha salarial alude a la distancia en la retribución media (salario más complementos) de mujeres y hombres. La brecha salarial no tiene en consideración para el análisis de dichas diferencias retributivas factores de tipo personal (nivel de formación, experiencia laboral, antigüedad, etc.), del puesto de trabajo (funciones realizadas, nivel de responsabilidad, tipo de contrato o jornada, etc.) y/o de la empresa para la que se trabaja (tamaño, tipo de actividad, etc.). En cambio, la discriminación retributiva entre mujeres y hombres es la parte de esa diferencia que no queda justificada por una distinta aportación de valor en el desempeño de un trabajo igual o de igual valor, y que solo puede ser explicada en función del sexo de la persona que lo realiza ${ }^{17}$. De ahí que la brecha salarial se suela denominar oficialmente «brecha salarial entre los géneros no ajustada», al no tener en cuenta todos los factores que influyen en esa diferencia. De ahí que el concepto «brecha salarial» resulte sesgado a la hora de analizar la discriminación retributiva en sentido estricto, y, al propio tiempo, incompleto, ya que el sistema de salario por hora utilizado para calcular dicha brecha puede enmascarar también diferencias sobre las cuales no se lleva un control específico, como las pagas extra, los complementos por rendimiento o las remuneraciones especiales en temporadas concretas. A pesar de la importancia que reviste deslindar ambos conceptos, tanto en la teoría como en la práctica estadística, no se ha realizado un estudio de qué porcentaje de brecha salarial obedece a prácticas discriminatorias directas o indirectas en sentido estricto, ni a nivel comunitario ni nacional ${ }^{18 .}$

${ }^{16}$ Según la EPA de los cuatro trimestres de 2013, las mujeres representan el 73,26\% del trabajo a tiempo parcial en nuestro país.

${ }^{17}$ Vid., GARCÍA TRASCASAS, A.: «Retribución y no discriminación por razón de sexo. Algunas reflexiones en torno a la negociación colectiva», en AAVV (A. FIGUERUELO BURRIEZA dir.), Perspectiva de género en la negociación colectiva: análisis por sectores feminizados y masculinizados», Bomarzo, Albacete, 2013, p. 80.

${ }^{18}$ Sí se realizó un estudio desagregado de las causas de la brecha salarial, en cambio, en Reino Unido en 2011, quedando formulada en porcentajes la contribución de cada una de dichas causas a la brecha salarial. El Parlamento de la UE, a pesar de la ausencia de estudios propios al respecto, en la Resolución del Parlamento Europeo de 24 de mayo de 2012, con recomendaciones destinadas a la Comisión sobre la aplicación del principio de igualdad de retribución entre trabajadores y trabajadoras para un mismo trabajo de igual valor, señala que "según el análisis de los expertos, aproximadamente la mitad de la diferencia salarial se debe a la discriminación directa e indirecta» (Considerando B). 
Según datos del INE, la brecha salarial entre mujeres y hombres en España, aunque muestra una ligera tendencia a su reducción en los últimos años, constituye un fenómeno persistente ${ }^{19}$. De ahí que algunos autores hayan calificado la discriminación retributiva por razón de sexo como paradigma de discriminación sistémica ${ }^{20}$.

El análisis de este fenómeno ha de partir necesariamente de la perspectiva adoptada por la Comisión Europea en el Informe de 6 de diciembre de 2013, relativo a la aplicación de la Directiva 2006/54/CE, del Parlamento Europeo y del Consejo, de 5 de julio de 2006, relativa a la aplicación del principio de igualdad de oportunidades e igualdad de trato entre hombres y mujeres en asuntos de empleo y ocupación. En la misma pone de manifiesto que, si bien el principio de igualdad de retribución ha sido objeto de plasmación formal en los instrumentos jurídicos nacionales de los Estados miembros (legislación en materia de igualdad, códigos laborales, convenios colectivos de trabajo), la aplicación práctica del principio plantea problemas. Ello conduce a la Comisión a alejarse de planteamientos puramente formalistas y a adoptar una visión más profunda, más sustancial y analítica, para tratar de ahondar en los problemas jurídico-técnicos y/o empíricos que, en la praxis, impiden la prosecución efectiva de la igualdad retributiva. En esta línea, la Comisión identifica tres factores que pueden estar impidiendo la efectividad de dicho principio: la falta de claridad sobre el concepto de «trabajo de igual valor»; la falta de transparencia en los sistemas de remuneración; y los obstáculos procesales.

\section{El concepto de trabajo de igual valor y la transparencia salarial: examen en dos niveles}

A. A nivel de negociación colectiva

Nuestro Derecho del Trabajo no define que ha de entenderse por trabajo de igual valor ${ }^{21}$, limitándose a sentar dicho principio en el

${ }^{19}$ Plan estratégico de Igualdad de Oportunidades 2014-2016, p. 15, disponible en http://www.inmujer.gob.es/actualidad/PEIO/docs/PEIO2014-2016.pdf

${ }^{20}$ CABEZA PEREIRO, J.: La discriminación retributiva por razón de sexo como paradigma de discriminación sistémica, en Lan Harremanak/25 (2012), pp. 79 a 98.

${ }^{21} \mathrm{Al}$ contrario de lo que sucede en otros ordenamientos de nuestro entorno, como Francia, Reino Unido o Suecia. En Francia, según el Art. 140-2 del Code du Travail: "se consideran de igual valor los trabajos que exigen a los trabajadores un conjunto similar de conocimientos profesionales acreditados por un título, un diploma o una práctica profesional, de capacidades adquiridas por la experiencia, de responsabilidades y de carga física o nerviosa». 


\section{SANDRA GARCÍA LOMBARDÍA}

artículo 28 del Estatuto, por lo que su interpretación queda en manos de los órganos jurisdiccionales nacionales. La Jurisprudencia comunitaria ha sentado pautas relevantes al respecto, adoptando una perspectiva cualitativa, en cuanto exige la comprobación de una serie de factores, como la naturaleza del trabajo, las condiciones de formación y las condiciones laborales, a fin de determinar si los trabajadores se encuentran en una situación comparable ${ }^{22}$. Sin embargo, como pone de manifiesto GARCÍA TRASCASAS ${ }^{23}$, la comparación de trabajados diferentes no tarea fácil, según ha declarado el propio Tribunal Constitucional (SSTC 145/91, 58/94, 286/94, 147/95), entrañando importantes dificultades valorativas desde el punto de vista del juicio de igualdad.

La aplicación de la doctrina del trabajo de igual valor en la definición de los criterios de clasificación profesional y de valoración de puestos de trabajo exige no solo que se utilicen criterios comunes para uno y otro sexo, sino que los criterios ponderados sean neutros, es decir, que no generen un impacto adverso o perjudicial para el colectivo femenino, como ocurre cuando se recurren a criterios de evaluación sexualmente caracterizados, como el esfuerzo físico (SSTC 145/91 Y 58/94), y se desprecian criterios más neutros en cuanto al impacto de género, como el cuidado, atención, meticulosidad, dedicación, concentración o carga mental, precisión, destreza, etc. Buena prueba de la dificultad que entraña la valoración de la neutralidad de ciertos criterios, es la existencia de complementos que, si bien han sido legitimados por la jurisprudencia comunitaria ${ }^{24}$, han sido fuertemente criticados por la doctrina, en cuanto entrañan un impacto adverso para el colectivo femenino. Es el caso de los complementos vinculados a la flexibilidad o adaptabilidad a horarios o lugares de trabajo variables, dado que estas circunstancias dificultan la conciliación de la vida familiar y laboral y por tanto, con la asunción mayoritariamente femenina de responsabilidades familiares y cargas domésticas. Lo mismo ocurre con el complemento de antigüedad, debido a la más reciente incorporación de las mujeres al mercado de trabajo y la elevada temporalidad que afecta al empleo femenino ${ }^{25}$.

${ }^{22}$ Entre otras, SSTJCE de 31/05/1995, asunto Royal Copenhagen, C 400/93; de 23/06/2001, asunto Brunnhofer, c. 381/99.

${ }^{23}$ Op. cit. p. 86

${ }^{24}$ Sentencias del TJCE de 17 de octubre de 1989, asunto Danfoss, C 109/88 y de 3 de octubre de 2006, asunto Cadman, C-17/05.

${ }^{25}$ Entre dicho sector doctrinal crítico con tales complementos, véase FERNÁNDEZ PROL, F.: «Igualdad por razón de sexo/género en la retribución y en los beneficios sociales», en AAVV (LOUSADA AROCHENA, coord..): El principio de igualdad en la negociación colectiva, Ministerio de Trabajo e Inmigración, Madrid, 2008, pp. 195 a 203. 


\section{El PaPel de la InsPección de Trabajo y SEguridad Social...}

A pesar de la existencia de guías de buenas prácticas para garantizar la igualdad retributiva a través de la correcta valoración de puestos de trabajo, a nivel internacional, comunitario y nacional ${ }^{26}$, la negociación colectiva no ha hecho uso de la posibilidad de incluir en el articulado convencional de referencia alguna a los métodos de valoración utilizados, la descripción de los factores que determinan la inclusión en un grupo, categoría, nivel profesional o puesto de trabajo, y las cualidades evaluadas en cada factor ${ }^{27}$. Algunos convenios no hacen siquiera mención alguna en cuanto a la igualdad y no discriminación entre hombres y mujeres; otros sí la hacen, pero sin abordar la cuestión retributiva específicamente; y la mayoría se limita a consagrar cláusulas genéricas de «igualdad retributiva por trabajos de igual valor», sin explicitar cómo ha sido aplicado o deba aplicarse dicho principio en la valoración de trabajos en el propio convenio y en las empresas del sector. De hecho, la evolución de la negociación colectiva revela un progresivo desinterés por esta cuestión, patente en los sucesivos Acuerdos Interconfederales para la Negociación colectiva. En los de 2003, 2005 y $2007^{28}$ se dedicaba un capítulo específico a la igualdad de trato en el empleo y asuntos retributivos, previendo un conjunto de buenas prácticas, entre las que destaca «el estudio y, en

${ }^{26} \mathrm{Vid}$., Guía detallada de la OIT para la promoción de la igualdad salarial por medio de una evaluación no sexista de los empleos, publicada por la OIT en 2008; Comunicación de la Comisión Europea: Código práctico sobre la aplicación de la igualdad de retribución entre hombres y mujeres para un trabajo de igual valor, COM (96) 336 final; y Guía 1 de buenas prácticas para garantizar la igualdad retributiva, publicada por el Ministerio de Trabajo y Asuntos Sociales en 2001, que establece un conjunto de recomendación y buenas prácticas dirigidas a los interlocutores sociales y a los empleadores, y una lista de control para detectar la discriminación salarial en la valoración de puestos de trabajo. Asimismo, en la reciente Recomendación de la Comisión, de 7 de marzo de 2014, sobre el refuerzo del principio de igualdad de retribución entre hombres y mujeres a través de la transparencia (DOUE de 8 de marzo), se establece que los Estados miembros deben animar a los empresarios y a los interlocutores sociales a introducir sistemas de evaluación y clasificación de empleos no sexistas (Recomendación n..$^{\circ} 11$ )

${ }^{27}$ Uno de los escasos ejemplos de convenios de sector que sí definen con cierto detalle los factores de valoración de grupos profesionales lo encontramos en el sector de la industria química (vid., Artículo 22 del XVII Convenio colectivo general de la industria química, BOE de 9 de abril de 2013)

${ }^{28}$ Publicados en BOE de 24/02/2003; de 16/03/2005; y de 24/02/2007, respectivamente. Llama la atención que en el ANC de 2003 se reconozca por primera vez que la negociación colectiva ha servido en ocasiones de fuente de discriminaciones retributivas indirectas para las mujeres: Las formas directas de discriminación laboral hacia las mujeres suelen ser residuales en los textos de los Convenios. Sin embargo, en el marco de los Convenios Colectivos hay discriminaciones de carácter indirecto y comporta especial dificultad constatar su existencia, dado que exigiría evaluar si de la aplicación de las medidas convenidas se derivan efectos negativamente desiguales para el colectivo femenino con respecto al masculino(Capítulo VI). 


\section{SANDRA GARCÍA LOMBARDÍA}

su caso, el establecimiento de sistemas de selección, clasificación, promoción y formación, sobre la base de criterios técnicos, objetivos y neutros por razón de género». Sin embargo, los Acuerdos para el Empleo y Negociación Colectiva 2010-2012 y 2012-2014 guardan un absoluto silencio al respecto, centrándose en la recuperación del empleo, el incremento de la competitividad y la moderación salarial.

Como señala VALDES DAL-RE, «las declaraciones generales o la reiteración de preceptos legales en la negociación colectiva carecen de idoneidad o aptitud para erradicar, por sí mismas, las conductas discriminatorias». Si bien tales cláusulas pueden cumplir una función pedagógica, aportando visibilidad al derecho antidiscriminatorio, presentan el peligro de que los interlocutores sociales descuiden la función reguladora del convenio en esta materia ${ }^{29}$. En efecto, si los interlocutores sociales se contentan con la mera transcripción de cláusulas generales y declaraciones de voluntad que nada aportan a lo ya preceptuado por la ley, se aferran a un formalismo que pueden ser confundido fácilmente con desidia o desinterés, al soslayar el papel fundamental que les compete para la realización efectiva de la igualdad en las relaciones laborales a través del desarrollo de la negociación colectiva. Para ello es imprescindible dotar de contenido sustancial a tales declaraciones, ahondar en su significado, perfilarlo, definirlo, clarificarlo, ampliar las genéricas competencias de los representantes legales de los trabajadores en esta materia y articular nuevos mecanismos de control no previstos por la ley ${ }^{30}$.

Las causas de la escasa acogida que esta cuestión ha tenido entre los interlocutores sociales son variadas. Sin duda, en los últimos años, la crisis económica ha provocado un desvío de la atención de los mismos hacia otros problemas, pero indudablemente existen razones más profundas. No puede obviarse que el recurso a los métodos de clasificación profesional y de valoración de puestos de trabajo desde la perspectiva de género exige que los negociadores dispongan de formación y conocimientos especializados en la materia, así como de experiencia en el manejo de conceptos claves en la tutela antidiscriminatoria. Por otro lado, no se trata de una tarea sencilla, especialmente cuando se trata de negociación de ámbito supraempresarial, pues requiere que

${ }^{29}$ VALDES DAL-RE, F.: Igualdad de género y relaciones laborales: entre la ley y la negociación colectiva, Reus, Madrid, 2010, pp. 58 a 60

${ }^{30}$ En esta línea, la Guía de buenas prácticas para garantizar la igualdad retributiva, publicada por el Ministerio de Trabajo y Asuntos Sociales en 2001, declaraba como «no es suficiente introducir cláusulas declarativas de igualdad en los convenios que se limiten a reproducir la prohibición de discriminación por razón de sexo, sino que es necesaria la paralela introducción de cláusulas de control». 
los negociadores recaben información salarial y de las características de los puestos de trabajo de las empresas del ámbito correspondiente, a fin de proceder a un análisis de los requerimientos, aptitudes y factores y del valor que ha de atribuirse a cada uno de ellos que permita la definición de un sistema de clasificación profesional plenamente adaptado a las necesidades y particularidades del sector. Finalmente, no deben desdeñarse la eventual resistencia del banco empresarial a la introducción de elementos en la negociación que introducen una alta dosis de transparencia y objetividad en la valoración de puestos (y en la asignación de los correspondientes niveles salariales) que, a la postre, van a redundar en una considerable reducción del margen de discrecionalidad del empresario en esta materia.

B. A nivel de empresa: la falta de transparencia de la estructura retributiva

Aún en los casos en que la negociación colectiva hubiese abordado y definido con rigor los criterios de valoración de grupos, categorías o puestos de trabajo, esto no garantizaría la transparencia retributiva en cada una de las empresas incluidas en su ámbito de aplicación, ya que en modo alguno limita la libertad empresarial para asignar otro tipo de complementos de naturaleza puramente voluntaria, es decir, distintos de los convencionalmente previstos y sin perjuicio de éstos. En la práctica inspectora se ha detectado que tales complementos no son infrecuentes, adoptando variadas tipologías y denominaciones: complemento de puesto, complemento personal, primas, incentivos, plus de productividad, plus o complemento voluntario (absorbible o no). Los últimos estudios revelan que es precisamente en estos complementos, especialmente en los de cuantía variable vinculados al rendimiento, desempeño o productividad, donde radica el mayor porcentaje de brecha salarial. La brecha salarial es mayor si se mide por rendimiento $(41,3 \%)$ que por ganancia media por hora $(19,3 \%)^{31}$. Barth $^{32}$ señala que los esquemas de remuneración basados en la productividad individual incrementan la desigualdad salarial dentro de la empresa frente a otros que reducen la dispersión, como los sistemas de incentivos relacionados con el grupo o aquellos otros basados en la

${ }^{31}$ AAVV: Determinantes de la brecha salarial de género en España, Ministerio de Sanidad, Servicios Sociales e Igualdad, Madrid, 2012, p. 146.

${ }^{32}$ BARTH, ERLING, BRATSBERG, BERNT, HAEGELAND, TORBJORN y RAAUM, ODDBJORN, "Performance Pay and Within-Firm Wage Inequality» (2009). IZA Discussion Paper No. 4137. Disponible en SSRN: http://ssrn.com/abstract=1395244

(C) UNED. Revista de Derecho UNED, núm. 16, 2015 
negociación sindical. SIMÓN, LOBO y SANROMÁ ${ }^{33}$ (2008) señalan que el origen fundamental de las diferencias salariales radica en las características del establecimiento así como en factores inobservables. Dolantes y De la Rica ${ }^{34}$ señalan que en materia de remuneración por rendimiento más que segregación parece existir «una excesiva capacidad de negociación por parte de la empresa».

Nos hallamos por tanto ante la posible existencia de estructuras retributivas basadas en la voluntad del empresario, ajenas a la negociación colectiva, y que quedan a extramuros de las facultades de información, fiscalización y vigilancia de los representantes de los trabajadores en la empresa. El Estatuto de los Trabajadores no establece que los representantes de los trabajadores, unitarios y sindicales, tengan derecho a recibir información sobre la estructura retributiva aplicada en la empresa, de tal suerte que podrían estar abonándose complementos voluntarios a determinados trabajadores sin que sus representantes y el resto de la plantilla tengan conocimiento de ello. Del mismo modo, no se establece la obligación de realizar una valoración de puestos de trabajo que permita verificar la adecuación entre la estructura retributiva aplicada y los requerimientos de cada puesto (y en particular, si los factores tenidos en consideración para anudar determinados complementos o una escala salarial superior son discriminatorios por carecer de neutralidad y justificación). El artículo 64.5 f) del ET se limita a establecer un derecho de información y consulta (mediante emisión de informe) de los representantes legales de los trabajadores, si el empresario decidiese realizar una valoración de puestos de trabajo o modificar la ya implantada. Pero en cualquier caso, la decisión de establecerla o no corresponde al empresario.

En cuanto a la implantación y revisión de los sistemas de estudios de tiempos, sistemas de primas e incentivos, el artículo 64.5f) del Estatuto de los Trabajadores establece el derecho del comité de empresa (o en su caso, de los delegados de personal, ex artículo 62.2 del ET) a «emitir informe con carácter previo a la ejecución por parte del empresario de las decisiones adoptadas por este» en las materias descritas. Este derecho de la representación legal de los trabajadores presupone la obligación empresarial de proporcionar a aquellos información so-

${ }^{33}$ SIMÓN, HIPÓLITO J.; LOBO, Raúl Ramos y SANROMÁ, Esteban: «Evolución de las diferencias salariales por razón de sexo,» Revista de Economía Aplicada, Universidad de Zaragoza, Departamento de Estructura Económica y Economía Publica, vol16(3), 2008, pag. 37-68

${ }^{34}$ AMUEDO-DORANTES, C. y S. De la RICA: «The Impact of Gender Segregation on Male-Female Wage Differentials: Evidence from Matched Employer-Employee Data for Spain» IZA Discussion Paper No. 1742, 2005. 
bre dicha decisión y sobre todos los extremos de la misma que sean relevantes («con un contenido apropiado») y obtener una respuesta justificada a su eventual informe, con la posibilidad de contrastar sus puntos de vista y opiniones (apartado 6 del articulo 64 del ET).

Sin embargo, en la práctica no es en absoluto infrecuente que la actuación inspectora detecte la existencia de complementos salariales vinculados al rendimiento (productividad, primas, incentivos) sin que la empresa haya elaborado y publicitado ningún documento donde aparezcan definidos y configurados tales complementos y sus elementos esenciales: criterios de asignación y devengo, de determinación de su cuantía y sistemas o módulos de medición de tiempos o resultados empleados para dicho cálculo. Y si en dicha empresa no existen representantes legales de los trabajadores, ninguna falta puede imputarse a la actuación empresarial, pues el precepto no establece que el empresario que aplique tales sistemas esté obligado a documentarlos y definirlos y, en suma, a dotar de transparencia la aplicación de los mismos (solo debe informar a los representantes cuando los hay). Y cuando existen representantes legales de los trabajadores que no han sido informados al respecto, de lo único de lo que podemos hablar es de una transgresión de los derechos de información y consulta de aquellos.

La inexistencia de una obligación legal empresarial de transparentar la estructura retributiva aplicada en la empresa y de proporcionar datos salariales a la representación legal de los trabajadores aboca a ésta a permanecer en el desconocimiento de la situación retributiva en la empresa. De poco sirve que el artículo 64.7 a) $3 .^{\circ}$ del ET atribuya a los representantes de los trabajadores la genérica competencia de vigilancia del respeto y aplicación del principio de igualdad de trato y de oportunidades entre mujeres y hombres si no le proporciona los instrumentos necesarios para llevar a efecto dicha labor de vigilancia. El apartado 3 de dicho precepto se limita a señalar que tendrá derecho a recibir información, al menos anualmente, relativa a la aplicación en la empresa del derecho de igualdad de trato y de oportunidades entre mujeres y hombres, entre la que se incluirán datos sobre la proporción de mujeres y hombres en los diferentes niveles profesionales, así como, en su caso, sobre las medidas que se hubieran adoptado para fomentar la igualdad entre mujeres y hombres en la empresa y, de haberse establecido un plan de igualdad, sobre la aplicación del mismo. No se concreta en qué consiste tal derecho de información, ni su contenido y límites y, por supuesto, no se hace referencia alguna a que incluya el derecho a recibir datos salariales (ni en abstracto ni concretos). 
El mismo efecto se produce en relación con las trabajadoras que eventualmente puedan estar siendo víctimas de una discriminación: difícilmente podrán llegar a la convicción, ni siquiera a la sospecha, de estar siendo discriminadas cuando les está vetado el acceso a los datos salariales de quienes ocupan puestos de trabajo análogos. La cuestión se dificulta aún más si tenemos en cuenta que el tertium comparationis no tiene por qué ser el mismo puesto de trabajo, sino todos aquellos puestos de trabajo de la empresa que tengan el mismo valor, pues si no existe una definición clara, transparente y pública de la valoración de los puestos de trabajo por parte de la empresa el trabajador no podrá comprobar si efectivamente el tratamiento salarial dispensado a los titulares de tales puestos de trabajo es discriminatorio o no.

La trascendencia de estos obstáculos para la consecución de la igualdad salarial efectiva ha llevado a la Comisión europea a aprobar una Recomendación ${ }^{35}$ para reforzar el principio de igualdad de retribución entre hombres y mujeres a través de la transparencia, en la que se pone el acento en la importancia de clarificar los criterios de evaluación para comparar empleos diferentes, el uso de sistemas de evaluación y clasificación de empleos no sexistas, transparentar las categorías salariales y garantizar la participación e información de los representantes de los trabajadores y de los propios trabajadores en estas materias. En ella se establece que Los Estados miembros deben alentar a los empleadores públicos y privados y a los interlocutores sociales a que adopten políticas de transparencia sobre la composición y las estructuras salariales, deben establecer medidas específicas para promover la transparencia salarial, establecer medidas para garantizar el derecho de los empleados a obtener información sobre los niveles salariales los Estados miembros deberán precisar en su legislación el concepto de «trabajo de igual valor». El valor del trabajo deberá evaluarse y compararse utilizando criterios objetivos tales como los requisitos educativos, profesionales y de formación, la cualificación, el esfuerzo y la responsabilidad, los trabajos realizados y la naturaleza de las tareas en cuestión.

A pesar del carácter no vinculante de las recomendaciones comunitarias, las medidas propuestas por la Comisión deberían hallar eco en una reforma de la normativa laboral en esta dirección, pues así lo exige una interpretación funcional del principio de transversalidad. Una vez detectados los obstáculos jurídicos que empecen a la consecución de la erradicación de la discriminación retributiva, la aplica-

${ }^{35}$ Recomendación de la Comisión, de 7 de marzo de 2014, sobre el refuerzo del principio de igualdad de retribución entre hombres y mujeres a través de la transparencia. 
ción del principio de transversalidad requiere que aquéllos sean removidos, adoptando para ello las medidas de política legislativa laboral que sean precisas.

No obstante, se trata esta de una medida que puede plantear problemas desde la perspectiva de los derechos fundamentales a la intimidad y, sobre todo, a la protección de datos de carácter personal. El TC, en la sentencia 142/1993, de 22 de abril, analizó y legitimó la constitucionalidad del artículo 1.2 de la Ley 2/1991, sobre derechos de información de los representantes de los trabajadores en materia de contratación, que establece la obligación empresarial de incluir en la copia básica de los contratos de trabajo la retribución pactada, declarando que «Las retribuciones que el trabajador obtiene de su trabajo no pueden en principio desgajarse de la esfera de las relaciones sociales y profesionales que el trabajador desarrolla fuera de su ámbito personal e intimo, para introducirse en este último, y hay que descartar que el conocimiento de la retribución percibida permita reconstruir la vida intima de los trabajadores...». Esta doctrina se ha ido aquilatando en sentencias posteriores del TS, como la de 19 de febrero de 2009 y 3 de mayo de 2011.

De la doctrina constitucional anteriormente consignada resulta que la retribución o salario no es un dato personal ni íntimo susceptible de reserva para salvaguardar el respeto a la intimidad. Como ha recordado la sentencia de esta Sala de 19 de febrero de 2009, recurso $6 / 2008$, se trata de un elemento esencial del contrato de trabajo, de naturaleza contractual, laboral y profesional, no siendo necesario recabar el consentimiento previo del trabajador individual para que los representantes sindicales puedan acceder, en su caso, a dicho dato.

Ahora bien, deben realizarse dos precisiones: en esta última, se trataba de un caso en que dicha cesión de información gozaba de amparo en el convenio colectivo de aplicación. En el caso de la STS de 19 de febrero de 2009, el TS desestima el recurso presentado por el sindicato peticionario de información consistente en las retribuciones mensuales actualizadas al año en curso de todos los trabajadores de la empresa. El alto Tribunal considera que dicha petición no es admisible, pues ni la contempla el convenio colectivo, ni el sindicato ha expuesto una justificación concreta que hiciera necesario el conocimiento de los datos solicitados en relación con el ejercicio de las funciones que constitucionalmente tiene reconocidas ( $\mathrm{FJ} 6 .^{\circ}$ ), bastando con la transmisión por parte del empresario de la información aludida en el artículo 1.2 de la Ley 2/1991 (retribución pactada en contrato de trabajo), suministrada a través de la entrega a la representación legal de los trabajadores de la copia básica de los contratos de trabajo. 
No cabe duda de que, a la luz de la vigente Ley Orgánica 15/1999, la cesión de datos salariales concretos, fuera de lo que pueda reconducirse a la retribución consignada en el contrato de trabajo, plantea problemas en cuanto podría colisionar con el derecho fundamental a la protección de datos de carácter personal, en cuanto derecho fundamental autónomo del derecho a la intimidad del artículo 18.1 de la Constitución ${ }^{36}$.

Tal y como determina el artículo 11.1 de la Ley Orgánica 15/1999, «los datos de carácter personal objeto del tratamiento solo podrán ser comunicados a un tercero para el cumplimiento de fines directamente relacionados con las funciones legítimas del cedente y del cesionario con el previo consentimiento del interesado». Esta regla de consentimiento solo se verá exceptuada en los supuestos contemplados en el artículo 11.2, siendo aplicable al supuesto de hecho planteado el previsto en el apartado a), aquellos casos en que una norma con rango de Ley dé cobertura a la cesión o el previsto en el apartado c) «Cuando el tratamiento responda a la libre y legítima aceptación de una relación jurídica cuyo desarrollo, cumplimiento y control implique necesariamente la conexión de dicho tratamiento con ficheros de terceros. En este caso la comunicación sólo será legítima cuando se límite a la finalidad que lo justifique.

En base a lo dispuesto en el apartado c) de dicho precepto, la cesión no precisa consentimiento cuando el derecho de información de la representación legal de los trabajadores está contemplada en convenio colectivo, en la medida en que este constituye una de las fuentes de la relación laboral a la que el trabajador está sujeto, sin perjuicio de que tales datos solo puedan ser utilizados por los representantes para el ejercicio de la función que constitucionalmente tienen atribuida, que deban aplicar las garantías previstas en la propia Ley Orgánica para su tratamiento y sin perjuicio del derecho de oposición que individualmente puede ejercer cada trabajador ${ }^{37}$.

Sin embargo, la cesión de datos salariales sin consentimiento del trabajador al Comité de empresa o delegados de personal, a falta de una previsión legal concreta, salvo la genérica competencia de «vigi-

${ }^{36}$ Vid., SSTC 254/1993, de 20 de julio (FJ 7..$^{\circ}$ ); 11/1994 (FJ4. ${ }^{\circ}$ ); 94/1998, de 4 de mayo (FJ 6. ${ }^{\circ}$ ); 202/1999, de 8 de noviembre (FJ 2. ${ }^{\circ}$ ) y, sobre todo, la 292/2000, de 30 de noviembre, que recoge y desarrolla la doctrina existente al respecto, delimitando el objetivo, contenido y límites de ambos derechos fundamentales.

${ }_{37}$ Así se mantiene en el Informe 252/2006, de la Agencia Española de Protección de Datos. 
lar el cumplimiento de la legislación laboral ${ }^{38}$, sí puede plantear importantes problemas de constitucionalidad. Incluso la introducción por el legislador de una específica obligación empresarial de informar sobre los salarios mensuales concretos (con especificación del alcance y cuantía de sus diversas partidas) de cada trabajador podría suscitar un conflicto entre derechos fundamentales (el derecho fundamental a la protección de datos y, de otro lado, los derechos fundamentales a la libertad sindical y a la prohibición de discriminación, pues esta sería la finalidad específica de dicha medida). La STC 292/200, de 30 de noviembre, ante el eventual conflicto entre el derecho fundamental a la protección de datos y otros derechos fundamentales, exige que «sus limitaciones estén fundadas en una previsión legal que tengan justificación constitucional y sean proporcionadas» (F. J. 16. ${ }^{\circ}$ ). Las más recientes Sentencias del TC 96/2012 y 241/2012 aplican la técnica tradicionalmente seguida por dicho Tribunal ante la colisión de derechos fundamentales, sometiéndola al triple juicio de constitucionalidad (de idoneidad, de proporcionalidad y de necesidad):

- Juicio de idoneidad: consistente en que la medida (el acceso al sueldo de los trabajadores) sea susceptible de conseguir el fin propuesto (que los representantes puedan cumplir la finalidad de vigilar en la empresa la aplicación del principio de igualdad entre mujeres y hombres), finalidad que parece cumplirse, puesto que no hay medida más idónea para ello que la posibilidad por parte de aquellos de acceder a los datos salariales concretos de hombres y mujeres.

- Juicio de proporcionalidad: que la medida sea ponderada por derivarse de ella más beneficios o ventajas para el interés general que perjuicios sobre otros derechos. Efectivamente este juicio podría darse por cumplido ya que el derecho a la libertad sindical, en el cual se incardina el derecho a recibir información por parte de los representantes de los trabajadores, es de carácter colectivo mientras que el de los trabajadores a la protección de sus datos es individual. También reviste una dimensión colectiva y de interés general el cumplimiento de la legislación laboral, en cuya consecución los representantes de los trabajadores pueden desempeñar un papel crucial, y en particular, en el respeto y cumplimiento del principio de no discriminación retributiva por razón de sexo en las empresas.

${ }^{38}$ La STS de 19 de febrero de 2009, en su FJ 5. ${ }^{\circ}$, y siguiendo la senda marcada por el TC en anteriores resoluciones, señala que las competencias que señala el artículo 64 del ET no constituyen un numerus clausus, sino que pesa sobre los representantes de los trabajadores el «deber de mantener informados a sus representados «en todos los temas y cuestiones señalados... en cuanto directa o indirectamente tengan o puedan tener repercusión en las relaciones laborales» (art. 64.1.12 LET) 


\section{SANDRA GARCÍA LOMBARDÍA}

- Juicio de necesidad: la medida debe ser necesaria en el sentido, que no exista otra medida más moderada o menos restrictiva con el derecho fundamental a la protección de datos, para alcanzar el fin propuesto. Probablemente sea este el juicio de más difícil superación, ya que existen medidas que, no afectando a dicho derecho fundamental, servirían para cumplir la finalidad propuesta, como el procedimiento de disociación previsto en el artículo 3.f) de la LOPD ${ }^{39}$.

Conforme a este procedimiento podría establecerse la obligación legal de proporcionar a los representantes de los trabajadores los datos salariales mensuales (o con la periodicidad que se fije) de cada trabajador, eliminando toda referencia a su identidad, sustituyéndola por un código expresivo de su sexo, de tal forma que se posibilite el examen concreto de las cuantía retributivas y extrarretributivas de hombres y mujeres sin identificación de su concreto perceptor. Las cuantías vinculadas a un rendimiento o medición de tiempos o productividades deberían acompañarse de los documentos donde se recojan los datos de desempeño del trabajador del período en cuestión, a fin de comprobar la adecuación entre los mismos y las cuantías de los complementos vinculados. Las ventajas de este procedimiento son numerosas: permitiría una adecuada implementación del derecho (y deber) de los representantes de vigilar el cumplimiento en la empresa del principio de igualdad de trato sin afección de datos de carácter personal, sin excepción, con importantes consecuencias, como la imposibilidad de que ningún trabajador vete el acceso a sus datos a través del ejercicio del derecho de oposición (pues al no haber cesión de datos personales, no es aplicable dicho derecho), y de otro lado, permitiría estrechar la colaboración entre los representantes de los trabajadores y la Inspección de Trabajo, pues las funciones de unos y otros, lejos de ser excluyentes, deben concurrir y complementarse, coadyuvando así al incremento de la eficacia de la actuación inspectora. Con ello se daría debido cumplimiento a lo dispuesto en el artículo 5 del Convenio n. ${ }^{\circ} 81$ de la OIT, de 1947, sobre la inspección del trabajo ${ }^{40}$, que establece que la autoridad competente deberá adoptar medidas pertinentes para fomentar la colaboración entre los funcionarios de la Inspección y los trabajadores y sus organizaciones.

${ }^{39}$ Art. 3.f) LOPD: «Procedimiento de disociación: todo tratamiento de datos personales de modo que la información que se obtenga no pueda asociarse a persona identificada o identificable

${ }^{40}$ Ratificado por España mediante instrumento de fecha 30/05/1960. 


\section{Obstáculos procedimentales: inseguridad jurídica y acceso limitado a la prueba}

La Comisión europea ha llamado la atención sobre la escasez de procedimientos judiciales sustanciados ante los tribunales de los Estados miembros de la UE por discriminaciones retributivas por razón de sexo, con las cualificadas excepciones de Reino Unido e Irlanda, en que la litigiosidad en esta materia es destacable. Asimismo, enfatiza la Comisión sobre la excesiva duración en el tiempo de este tipo de procedimientos, de tal suerte que, una vez planteados, no hallan una respuesta judicial con la prontitud y celeridad que sería deseable. ${ }^{41}$ La Comisión reconduce los obstáculos procesales en los asuntos de igualdad de retribución a varias causas: largos y costosos procedimientos judiciales, plazos, ausencia de sanciones efectivas y de compensaciones suficientes, y el acceso limitado a la información necesaria para reclamar la igualdad salarial. Por ello conviene analizar si los instrumentos materiales y procesales que el ordenamiento pone a disposición de la lucha antidiscriminatoria son suficientes y eficaces para la consecución del fin para el que fueron creados. En definitiva, se trata de determinar si en nuestro derecho existen esos «obstáculos procesales» a que hace alusión la Comisión europea, y, en caso afirmativo, identificar donde radican.

No parece existir inconveniente alguno en cuanto a la legitimación activa, que corresponde tanto a los trabajadores individualmente perjudicados, durante la vigencia de la relación laboral o una vez terminada aquella (artículo 12.1 de la LOI), a los representantes de los trabajadores cuando el conflicto se ciña a su ámbito de actuación (artículos 64.7 a)1. ${ }^{\circ}$ del ET y 154 y 155 de la LJS), así como a los sindicatos y entidades públicas y privadas entre cuyos fines se halle la defensa y promoción de la igualdad de trato (177 LJS $)^{42}$. El cauce procedimental articulado por la legislación procesal laboral es el procedimiento preferente y sumario previsto para la tutela de los derechos fundamentales y libertades públicas (artículos 177 y ss LJS), por lo que estos asuntos deberían recibir un tratamiento procesal prioritario y ágil, dándoseles respuesta en un plazo temporalmente limitado. Por otro lado, la protección y blindaje de los trabajadores reclamantes frente a eventuales represalias, incluido el despido, por parte

${ }^{41}$ Informe de la Comisión al Consejo y al Parlamento Europeo sobre la aplicación de la Directiva 2006/54/CE del Parlamento Europeo y del Consejo, de 5 de julio de 2006, relativa a la aplicación del principio de igualdad de oportunidades e igualdad de trato entre hombres y mujeres en asuntos de empleo y ocupación, Bruselas, 06.12.13, $\operatorname{COM}(2013) 861$ final, pp. 8 y 11.

${ }^{42} \mathrm{Si}$ bien en el caso de sindicatos y entidades públicas y privadas, con restricciones. 


\section{SANDRA GARCÍA LOMBARDÍA}

del empresario ya se hallaba asegurada por la garantía de indemnidad, aplicada y desarrollada por la jurisprudencia social y positivizada en el artículo 7 de la LOI.

Sin embargo, no existen previsiones sobre cómo resolver una eventual situación de discriminación salarial una vez detectada por la Inspección de Trabajo y Seguridad Social y promovido el procedimiento de oficio. El objeto de este procedimiento es que el órgano judicial se pronuncie sobre el carácter discriminatorio de la conducta constatada en la actuación inspectora y sobre los perjuicios causados a los trabajadores a resultas de esta. Sin embargo, no comprende la demanda de las diferencias salariales dejadas de percibir por aquellos, que sólo podrán ser reclamadas por el trabajador interesado a través de la correspondiente acción de reclamación de cantidad. Y por otro lado, dicha sentencia tampoco ha de pronunciarse sobre los salarios que han de percibir pro futuro dichos trabajadores. La solución parece obvia: la empresa condenada deberá abonar idéntica retribución a hombres y mujeres en los grupos o categorías objeto de controversia. Ahora bien, no existe previsión jurídica o salvaguarda alguna de que dicha nivelación deba realizarse al alza o a la baja. Parece evidente que cuando la discriminación tenga su origen en un convenio o acuerdo colectivo, el grupo o categoría infravalorado deberá ser equiparado retributivamente al grupo o categoría objeto de comparación, y el empresario no podrá proceder a una reclasificación profesional o a la modificación de las cuantías retributivas unilateralmente, al ser fruto aquellas de la negociación colectiva. Cosa distinta ocurre cuando las diferencias retributivas vienen dadas por complementos voluntarios, susceptibles de ser reducidos, alterados o suprimidos unilateralmente por la empresa. Este problema no se producía con anterioridad a la reforma laboral de 2012, en que las condiciones salariales más beneficiosas no constituían materia modificable por voluntad unilateral del empresario. Tras la reforma del artículo 41 del ET la cuantía del salario y el sistema de remuneración establecida en acuerdos individuales o colectivos que no tengan el carácter de convenio estatutario (en cuyo caso su alteración solo podrá tener lugar conforme a las reglas establecidas en el artículo 82.3 del Estatuto de los Trabajadores, de acuerdo con el apartado 6) puede ser objeto de alteración unilateral por el empresario si concurren causas económicas técnicas organizativas o de la producción que lo justifiquen, considerando «tales las que estén relacionadas con la competitividad, productividad u organización técnica o del trabajo en la empresa» (artículo $41.1 \mathrm{ET}$ ). 
La nivelación al alza en muchos casos no será posible, en especial cuando los colectivos afectados son amplios (plantillas elevadas, altamente feminizadas) o las diferencias salariales son muy elevadas, pues ello podría abocar a la inviabilidad económica de la empresa. La nivelación a la baja (supresión o reducción de los complementos voluntarios) si bien teóricamente sería posible en vista del tenor literal del artículo 41.1 del ET, es discutible que se admisible a la luz de los límites de la buena fe, el abuso de derecho y el respeto a los derechos fundamentales. La solución que parece haber hallado eco en la jurisprudencia es la consistente en repartir el importe total del complemento o condición más beneficiosa entre todos los trabajadores afectados, lo cual supone que unos trabajadores verán recortado el importe de los mismos en beneficio del colectivo de trabajadores discriminados. La Sentencia del Tribunal Superior de Justicia de Galicia 194/2013, de 17 de diciembre, resuelve el conflicto colectivo surgido en una empresa conservera a raíz de una actuación inspectora que, habiendo constatado una discriminación salarial, requirió a la empresa para la corrección de la situación. Tanto la parte empresarial como la social admitieron que extender el importe del beneficio a todos los trabajadores sería inviable económicamente, ante lo cual la empresa optó por repartir el importe bruto anual de dicho beneficio entre todos los afectados, procediendo para ello a la modificación sustancial de condiciones de trabajo invocando causas económicas. El Tribunal da por buen esta solución, entendiendo justificada objetivamente la modificación, ya que con ella la empresa no pretende ahorrar costes o aumentar sus beneficios. No obstante, debe destacarse que la resolución adoptada por la sentencia de instancia acogía la postura contraria, por lo que la solución dista de ser pacífica.

La perspectiva de las posibles soluciones a la discriminación salarial no plantea una dimensión meramente jurídica, sino también económica, al representar un coste difícil de afrontar en las empresas, máxime en momentos como el actual en que prima el objetivo de la competitividad $^{43}$. Por ello, convendría que legislativamente se contemplasen ciertas garantías que dotasen de una dosis de certeza o seguridad a la solución del conflicto, así como mecanismos alternativos de resolución como el arbitraje obligatorio.

La Comisión también ha llamado la atención de las consecuencias obstaculizadoras del procedimiento que puede tener el acceso limitado a la información salarial por parte de los trabajadores. El mecanis-

${ }^{43}$ PÉREZ DEL RÍO, T.: Discriminación por razón de género y negociación colectiva, p.7, disponible en emakunde.euskadi.net/072-publicac/es/contenidos/información/pu-jornadas. 
mo formal de inversión de la carga de la prueba recogido en las legislación procesal para los casos de discriminación (a. 13 LOI y 96 de la LJS) puede verse virtualmente vaciado de contenido si los perjudicados no tienen acceso a la prueba. Y ello porque la inversión de la carga de la prueba, al contrario de lo que su nombre parece indicar, no supone una verdadera inversión del onus probandi (privilegio procesal que resultaría inadmisible al alterar el principio básico de igualdad de las partes en el proceso), sino un reparto de la carga de la prueba entre demandante y demandado. Precisamente por esta razón la doctrina la califica de semi-inversion de la carga de la prueba ${ }^{44}$, pues no exonera al demandante de aportar un panorama indiciario racional de la existencia de una diferencia de trato vinculada a alguno de los factores prohibidos pro el artículo 14 de la CE (STC 34/1984, FJ 1. ${ }^{\circ}$ ). Así, en la Sentencia de 26 de junio de 2001, asunto Brunnhofer, la reclamante alegaba una discriminación por razón de sexo por recibir una retribución inferior a la de un compañero situado en el mismo nivel retributivo. El TJUE señaló que la demandante debía probar al menos la percepción de una retribución inferior a la de su compañero y la realización de un trabajo de igual valor. Por tanto, la diligencia probatoria exigida a las demandantes en los casos de discriminación salarial no es desdeñable, entrañando una dificultad considerable habida cuenta de que ni pueden acceder a los datos salariales de sus compañeros y de que, a falta de una valoración de puesto de trabajo transparente y objetiva, es la demandante la que ha de proceder a tal calificación valorativa y probarla.

Buena prueba de la dificultad que entraña esta cuestión la encontramos en varios procedimientos judiciales que se sustanciaron ante los tribunales españoles entre 2008 y 2011, iniciados por un buen número de trabajadoras frente a una conocida empresa del sector de grandes almacenes de nuestro país, previa presentación de denuncia ante las Inspecciones de Trabajo de Madrid y Barcelona. Las trabajadoras denunciaban una discriminación sistemática de las mujeres en la promoción profesional en la empresa. Las sentencias que recayeron fueron profundamente contradictorias, influyendo en ello considerablemente la cuestión probatoria. Las SSTSJ de Madrid de 10/11/2008 y 22/04/2009 (ROJ 2109/2009) desestimaron las pretensiones de las demandantes, por entender que estas no habían aportado los indicios suficientes para desplazar la carga de la prueba a la parte demandada. Las actoras habían puesto de manifiesto como el Plan de Formación (el acceso a dichos cursos era imprescindible para promocionar, dependiendo de la evaluación positiva del superior jerárquico inmediato

${ }^{44}$ CANCIO ÁLVAREZ, M. D (coord.): op. cit., p. 570 
la selección de los trabajadores que podrían acceder al mismo) y los criterios de selección para la promoción no eran públicos, ni conocidos por la plantilla, ni se había informado al Comité de Empresa de los mismos. Pues bien, el Tribunal considera irrelevante la oscuridad y opacidad del sistema de promoción profesional de la empresa, ya que "la inexistencia de documentos en los que se hayan plasmado por escrito los criterios de la empresa para el ascenso por libre designación, cuestión a la que aluden los recursos, no debe considerarse un factor decisivo, ya que no existe norma legal ni convencional que obligue a que esos criterios consten por escrito, y lo relevante es que los criterios existan y se apliquen con habitualidad, y que no sean discriminatorios de forma directa ni indirecta» (FJ 2. ${ }^{\circ}$ ). La empresa sí expuso durante el procedimiento cuáles eran esos criterios determinantes para el ascenso (efectuar jornada completa y no reducida, en horario partido y flexible para encontrarse en su puesto en los momentos de apertura y cierre del establecimiento, prestar servicios en domingos y festivos y no solamente de lunes a viernes). Las recurrentes, con buen criterio, argumentaron que los factores de jornada partida, flexibilidad horaria, presencia en apertura y cierre, o participar en actividades formativas fuera de la jornada laboral «conducen a que las mujeres tengan más dificultades e impedimentos para cometer (sic) dichos cambios, sin que de por sí constituyan un factor justificativo de una mayor capacitación y profesionalidad para la promoción profesional», siendo constitutivos de una discriminación indirecta por razón de sexo, por provocar un impacto fuertemente adverso en el colectivo femenino, fundamentando todo ello en la jurisprudencia del TJUE. Sin embargo, el Tribunal considera que esta argumentación "es escasa», desestimando este motivo en base a que «los recursos no exponen suficientemente (ni hay tampoco prueba al respecto) las razones por las cuales los criterios empresariales(..) perjudican de forma generalizada a las mujeres con relación a los hombres, pero en todo caso subsistiría el criterio de evaluación individual de cada empleado, el cual no puede encerrar discriminación indirecta alguna, pues se trata de constatar las aptitudes de cada persona (FJ 3. ${ }^{\circ}$ ). Las demandantes no pudieron aportar prueba estadística, pues evidentemente el número de hombres y mujeres presentes en cada grupo profesional y la proporción de hombres y mujeres que ascendían en cada proceso no les eran accesibles, salvo a través de la actuación de la ITSS. Sin embargo, el informe emitido por esta, en el que sí constaban dichos datos estadísticos, no fue admitido como prueba por el Tribunal, arguyendo que aquel se emitió en 2004 y la demanda no fue presentada hasta el $2007\left(\mathrm{FJ} \mathrm{1.}{ }^{\circ}\right)$. 


\section{SANDRA GARCÍA LOMBARDÍA}

Paralelamente, se producían pronunciamientos completamente contradictorios en Barcelona. En esta Comunidad Autónoma fue la propia Administración laboral la que inició el procedimiento judicial de oficio, previo levantamiento de varias Actas de Infracción por parte de la ITSS de Barcelona, tras constatarse la existencia de una discriminación indirecta por razón de sexo en materia de promoción profesional en cuatro centros de trabajo del área metropolitana de Barcelona de esa misma empresa. Las cuatro demandas de oficio presentadas se acumularon ante el Juzgado de lo Social n. ${ }^{\circ} 13$ de Barcelona, que fueron estimadas íntegramente en Sentencia de $30 / 07 / 2007$, confirmada, tras haber sido recurrida por la empresa, por Sentencia del TSJ de Cataluña de 09/06/2010. Interpuesto recurso de casación ante el TS, fue resuelto por la Sentencia 5798/2011, de 18 de julio de 2011, cuya doctrina constituye todo un referente en esta materia ${ }^{45}$, al acoger de forma ejemplar la jurisprudencia comunitaria sobre prueba estadística, opacidad y neutralidad de los criterios, aplicando técnicas derivadas del concepto de impacto de género, como el test de sustitución o but for ${ }^{46}$. La prueba presentada por la Inspección de Trabajo pivotó sobre dos ejes: la prueba estadística, que revelaba una considerable desproporción entre el número de hombres y mujeres empleados en los grupos profesionales en disposición de promocionar al grupo superior, y el número de hombres y mujeres que efectivamente promocionaban al grupo superior, de tal manera que la presencia de mujeres en los grupos más bajos era abrumadora, disminuyendo en los grupos inmediatamente superiores, hasta prácticamente desaparecer en los escalones jerárquicos más altos. Ello ocurría porque a pesar de que el grueso de candidatos potenciales para promocionar eran mujeres, la gran mayoría de promocionados eran, finalmente, los hombres; la opacidad del proceder de la empresa en materia de ascensos, el secretismo con que se acordaban estos y que los mismos se realizaban principalmente por cooptación; por último, que los criterios exigidos por la empresa

${ }^{45}$ Es la única Sentencia, junto a STC 145/1991, citada como ejemplo de jurisprudencia española en materia de igualdad en el documento de trabajo anexo al Informe sobre la aplicación de la Directiva 2006/54/CE del Parlamento Europeo y del Consejo, de 5 de julio de 2006, relativa a la aplicación del principio de igualdad de oportunidades e igualdad de trato entre hombres y mujeres en asuntos de empleo y ocupación (Commission staff working document /* SWD/2013/0512 final */, disponible en http// eur-lex.europa.eu/legal-content/EN/ALL/?uri=CELEX:52013SC0512

${ }^{46}$ Consiste en identificar el efecto que produce en hombres y mujeres una decisión, práctica o procedimiento adoptada en cualquier área de gestión, permitiendo este análisis verificar si su resultado es discriminatorio. Existen precedentes en la aplicación de este test en la STS 4425/2009, de 23 de abril, que enjuició la interpretación dada por una empresa a los permisos por hospitalización de parientes. 
para promocionar (y que fueron puestos de manifiesto a resultas de la actuación inspectora, pues en la práctica empresarial, como ya se ha dicho, no eran públicos ni conocidos). El TS acepta la prueba estadística, citando la nutrida jurisprudencia comunitaria y constitucional que la ampara, declarando que la misma revela un «resultado anómalamente desproporcionada en perjuicio de las mujeres» (FJ 6. ${ }^{\circ}$ ), sin que exista una justificación objetiva y razonable, ya que los requisitos exigidos por la empresa para ser mando (trabajar a jornada completa, partida, con horario flexible y en domingos y festivos) no son conformes con la jurisprudencia comunitaria y nacional ${ }^{47}$ ni resultan justificadas, pues según el tenor del Convenio colectivo de aplicación no son necesarios para cubrir puestos de mando y responsabilidad ( de hecho, el Convenio colectivo de grandes almacenes permite que las personas con mando y responsabilidad flexibilicen su horario, retrasen o adelanten las horas de entrada y salida, o tengan más descanso a medio día, pudiendo ser sustituidos por un compañero con similar responsabilidad), y provocan un resultado discriminatorio, al impedir el ascenso de las mujeres porque, mayoritariamente, tienen contrato a tiempo parcial. Para reafirmar dicha conclusión, el Tribunal recurre al test de but for: «si condicionamos los ascensos a la realización de jornada completa pero partida y además flexible se está discriminando a la mujer porque, como tiene más dificultades para conciliar la vida familiar, se le están poniendo trabas para ascender que no tienen los hombres».

Este análisis comparativo del tratamiento judicial que se dio al mismo caso en ambas Comunidades puede servir como ejemplo de la relevancia que reviste el acceso de las partes a la prueba: el éxito o el fracaso del procedimiento en uno y otro caso no estribó en la existencia o inexistencia de discriminación, sino en la prueba de que disponían los demandantes, Administración Laboral, en un caso, y trabajadoras afectadas, en otro. La accesibilidad de la Inspección de Trabajo a la prueba es muy superior a la de los trabajadores o sus representantes unitarios o sindicales, y ello determinó el buen fin del procedi-

${ }^{47}$ Según la STC 22/1994, de 27 de enero (F. J. 4. ${ }^{\circ}$ ), «una abundante jurisprudencia de este Tribunal ha descartado que sean adecuadas las diferencias que se implantan atendiendo solo y exclusivamente al menor número de horas trabajadas, porque tomándose en cuenta solo este factor diferencial, se ignora el menor poder contractual de estos trabajadores atípicos y el dato, contrastado en la experiencia, de que en estos colectivos se concentran altos porcentajes de mano de obra femenina, con lo que la irrazonabilidad del factor diferencial se acentúa al entrar en juego la prohibición de discriminación, exigiéndose por tanto una más cuidadosa justificación de las desigualdades en este terreno, mediante la puesta de manifiesto de otros factores concomitantes que las expliquen, al margen solo del tiempo de trabajo inferior». 


\section{SANDRA GARCÍA LOMBARDÍA}

miento judicial en el primer caso y la desestimación de la pretensión en el segundo caso.

Queda por tanto puesto de manifiesto que la creación de un instrumento jurídico al servicio de la lucha contra la discriminación, como es esta semi-inversión de la carga de la prueba, carecerá de efectividad si no se acomete simultáneamente una revisión del ordenamiento laboral que, partiendo de la clarificación de las estructuras retributivas y la valoración de puestos de trabajo en las empresas, permita a las partes acceder a datos básicos para, en primer lugar, llegar a la conclusión del carácter discriminatorio de la práctica empresarial, y en segundo lugar, en caso de que la respuesta a la anterior cuestión sea positiva, recabar los datos suficientes para fundamentar judicialmente su pretensión. Debe valorarse positivamente la introducción por la Ley Orgánica 3/2007 en el artículo 64 del Estatuto de los Trabajadores el derecho de los representantes de los trabajadores de recibir información sobre los datos desagregados de hombres y mujeres en los diferentes niveles profesionales. El acceso a estos datos les permitirá examinar el grado de segmentación vertical en la empresa y determinar si existen indicios de discriminación por razón de sexo en la promoción profesional. No obstante, tales datos no son suficientes por sí solos, ya que es preciso completarlos con los datos desagregados sobre ascensos o promociones profesionales de unos y otros y con los criterios tenidos en cuenta por la empresa para dicha promoción.

En este sentido, la Inspección de Trabajo puede desarrollar una función esencial, en dos momentos:

- Previo a un posible procedimiento judicial, examinando la cuestión a instancia de los interesados (denuncia), procediendo al análisis de los datos aportados por aquellos y los que, en ejercicio de sus competencias, puede recabar el propio inspector. En cualquier caso, este fundamentará fáctica y jurídicamente su decisión en las correspondientes actas o informes, que pueden estimar la existencia de discriminación o no hacerlo. En este último caso, nada obsta para que los trabajadores planteen igualmente el caso ante los órganos judiciales, si bien también es posible que, en vista de las conclusiones alcanzadas por el inspector, abandonen su eventual pretensión de judicializar el asunto (con lo que la actuación inspectora habrá servido como eficaz medio de asesoramiento y de evitación de la litigiosidad). Si el inspector, por el contrario, detecta que la práctica empresarial es discriminatoria, procederá a la apertura de un procedimiento sancionador que, dada la presunción de certeza y veracidad de que gozan 
los hechos recogidos en las actas de infracción de la Inspección ${ }^{48}$, servirá como medio de prueba especialmente privilegiado y que provocará el inmediato desplazamiento de la carga de la prueba a la parte empresarial. Además, la Inspección podrá jugar un papel de promoción activa en la tutela del derecho fundamental mediante la incoación del procedimiento judicial de oficio, relevando a los interesados de la carga de judicializar el asunto, y sin perjuicio de que éstos puedan personarse como partes en dicho procedimiento.

- Posterior a la iniciación de un procedimiento judicial por los interesados, cuando estos han decidido acudir directamente a la jurisdicción social sin pasar antes por Inspección de Trabajo. En este supuesto, la intervención inspectora vendrá por la vía de la emisión de los informes y dictámenes a que aludía el artículo 95.3 de la derogada LPL $^{49}$ y de la vigente Ley de Jurisdicción Social, que el juez puede recabar de oficio, si lo estima oportuno, o a instancia de parte.

\section{CONCLUSIONES: EL PRINCIPIO DE TRANSPARENCIA COMO SUBPRINCIPIO DEL PRINCIPIO DE TRANSVERSALIDAD}

La Inspección de Trabajo y Seguridad Social constituye uno de los cauces más idóneos para luchar por la erradicación efectiva de la discriminación retributiva, tanto por la intensidad y continuidad de la actuación inspectora en esta materia, como por su accesibilidad a los agentes sociales y, sobre todo, por el alcance y amplitud de los instrumentos jurídicos de que dispone. Entre ellos destaca, ante todo, el procedimiento de oficio, que dispensa a los interesados de la carga de iniciar el procedimiento judicial y de procurar la prueba, sin perjuicio de su derecho a personarse en el procedimiento junto a la Administración Laboral.

Sin embargo, a lo largo de este trabajo se han puesto de manifiesto los obstáculos con que se topa este organismo para la detección de las situaciones de discriminación retributiva, que vienen determinadas por tres factores:

- La falta de transparencia salarial: las deficiencias en los derechos de información de trabajadores y agentes sociales sobre la es-

${ }^{48}$ Disposición adicional 4. ${ }^{\text {a }}$ de la Ley 42/1997, Ordenadora de la Inspección de Trabajo y Seguridad Social.

${ }^{49}$ Introducido por el apartado sesenta y cuatro del artículo décimo de la Ley 13/2009, de 3 de noviembre, de reforma de la legislación procesal para la implantación de la nueva Oficina judicial («BOE» de 4 de noviembre). 


\section{SANDRA GARCÍA LOMBARDÍA}

tructura y cuantías retributivas en las empresas se traduce en la virtual ausencia de denuncias en esta materia, al abocar al desconocimiento de la realidad salarial empresarial o, cuando menos, a un limitado acceso a la prueba necesaria para fundar la pretensión.

- La valoración de puestos de trabajo en las empresas a pesar de ser una herramienta básica para la comparación de puestos de trabajo y, por tanto, para la detección de la discriminación retributiva, ni es obligatoria en las empresas ni ha sido desarrollada a nivel de negociación colectiva.

- La existencia de cierta inseguridad jurídica en torno a la solución a las situaciones de discriminación retributiva, los complejos problemas económicos que pueden acarrear a las empresas y los conflictos colectivos que las propias soluciones pueden originar también explica las reticencias que los trabajadores y sus representantes puedan albergar de cara a denunciar una posible situación de esta índole.

Este conjunto de factores abocan a cierta «invisibilidad» de la discriminación retributiva, tanto para los perjudicados, sus representantes legales, sindicatos y para las propias Autoridades Laborales.

A los poderes públicos y, en particular, al legislador, corresponde remover los obstáculos para que la igualdad sea real y efectiva. El estudio realizado pone de relieve como el legislador ha delegado ciertas funciones básicas en esta materia en pro de la negociación colectiva, siendo el máximo exponente de esta tendencia la Ley Organica para la Igualdad Efectiva de Mujeres y Hombres. Sin embargo, la negociación colectiva ha demostrado no estar en condiciones de poder explotar todas las potencialidades ofrecidas por la Ley, ya que ésta no ha resuelto las cuestiones expuestas, que resultan básicas como punto de partida para la lucha antidiscriminatoria en materia retributiva. Estas cuestiones o condiciones constituyen un mínimo, que el Derecho del Trabajo ha de asumir y desarrollar en su papel tradicional de derecho tuitivo, con la misión de proporcionar a los agentes sociales unas bases solidas sobre las que construir fundadamente sus propuestas y reivindicaciones. No puede obviarse que la negociación colectiva es un proceso tendente a lograr un delicado equilibrio entre los intereses de la parte social y empresarial, y si carece de una base legislativa fuerte las propuestas de la parte social en esta materia pueden caer en saco roto en la dinámica negocial, al priorizarse otras materias consideradas hoy más urgentes o perentorias. Por ello, no basta con que la ley abra espacios a la negociación colectiva, sino que ha de procurar que estos espacios estén suficientemente revestidos de derechos y garantías. En materia de igualdad retributiva, dichas garantías pasan 
por la transparencia de la estructura y cuantías salariales y de la valoración de puestos de trabajo en las distintas empresas y sectores.

El Derecho antidiscriminatorio actual no se ha desgajado de cierto formalismo, al introducir en su estructura normativa todos los elementos garantistas exigidos por el Derecho Comunitario (inversión de la carga de la prueba, garantía de indemnidad, conceptos claros de los diversos tipos de discriminación), así como instrumentos más sofisticados para la lucha antidiscriminatoria (como los planes de igual$\operatorname{dad}^{50}$ ), pero no parece haber procedido a un análisis en profundidad de cuales pueden ser los obstáculos que invisibilizan en la práctica las situaciones de discriminación retributiva. Uno de estos obstáculos se salvaría transparentando la estructura salarial y la valoración de puestos de trabajo en la empresa, garantizando los derechos de información de los trabajadores y/o sus representantes legales en estas materias y posibilitando de esta forma su colaboración con la Inspección de Trabajo en la detección de la discriminación retributiva.

En este sentido, la exigencia de transparencia conecta directamente con el principio de transversalidad, concretamente con su vertiente funcional o material, que trasciende de la mera integración formal del principio de igualdad en todas las políticas y áreas de gestión, exigiendo un plus de naturaleza sustancial: reivindicar la habilitación legislativa de técnicas y herramientas adecuadas desde la perspectiva de género que permitan no solo erradicar las prácticas discriminatorias, sino también despejar los obstáculos o factores que las encubren o dificultan su detección. El principio de transparencia cobra así una nueva dimensión, como subprincipio del de transversalidad, en cuanto condición indispensable para que este último se vea implementado en toda su plenitud en los mecanismos jurídico-laborales de lucha contra la discriminación retributiva.

${ }^{50}$ La virtualidad práctica de la figura de los planes de igualdad, introducida $e x$ novo por el artículo 45 de la LOI, como fórmula de fomento de igualdad en las empresas es de eficacia cuantitativamente muy limitada, dado que solo vienen obligadas a elaborarlos las empresas de más de 250 trabajadores. Según el último retrato de PYMES publicado por la Dirección General de Industria y de la Pequeña y Mediana Empresa en enero de 2014 (disponible en www.ipyme.org), el 99,9\% de nuestro tejido empresarial viene constituido por empresas de menos de 250 trabajadores (PYMES). Las empresas que cuentan con plantillas de trabajadores por encima de dicho umbral representan únicamente un $0,1 \%$ del tejido empresarial español y el 0,2\% del comunitario. En el plano cualitativo, tanto a nivel de diagnóstico como de contenido de los planes, se han detectado numerosas deficiencias. Al respecto, vid., ENCARNA BODELÓN Y NOELIA IGAREDA: Los planes de igualdad en tiempos de crisis. Problemas de aplicación y carencias conceptuales, Dykinson, Madrid, 2013. 


\section{SANDRA GARCÍA LOMBARDÍA}

A la luz de las ideas expuestas, cabe concluir que, al menos en lo que concierne a la normativa laboral, el principio de transversalidad viene siendo aplicado en un sentido más formal que funcional, puesto que a pesar de haberse procedido a la transposición formal de las disposiciones de la Directiva 2006/54/CE, no se ha procedido conjuntamente a un análisis material de los problemas prácticos que plantea la discriminación retributiva y de los instrumentos complementarios que resultan indispensables para que los mecanismos previstos en la Directiva puedan desplegar toda su virtualidad. En este sentido, cabe valorar muy positivamente la posición adoptada por la Comisión Europea en el Informe de 6 de diciembre de 2013, al marcar un punto de inflexión hacia esa vertiente funcional del mainstreaming de género, al entender que no puede considerarse adecuadamente transpuesta dicha Directiva a los derechos nacionales de los Estados miembros mientras el legislador y los interlocutores sociales no analicen y den una respuesta jurídica adecuada a los problemas prácticos descritos. En cambio sí resulta criticable la utilización de técnicas propias de «soft law» para transmitir a los Estados miembros la necesidad de acometer tal tarea, puesto que según la tesis defendida en el presente trabajo, el principio de transparencia, en la medida en que trae causa del principio de transversalidad adquiere en nuestro derecho la misma naturaleza imperativa que éste, por mor de lo dispuesto en el artículo 15 de la Ley Orgánica 3/2007, y por tanto, debe informar necesariamente una revisión de la normativa laboral antidiscriminatoria en materia retributiva.

\section{BIBLIOGRAFÍA}

AAVV (M. ${ }^{a}$ D. Cancio Alvarez, coord.): Estudios interdisciplinares sobre igualdad, Iustel, Madrid, 2011.

AAVV (A. FIGUERUELO BURRIEZA dir.), «Perspectiva de género en la negociación colectiva: análisis por sectores feminizados y masculinizados», Bomarzo, Albacete, 2013.

AAVV (LOUSADA AROCHENA, coord.): El principio de igualdad en la negociación colectiva, Ministerio de Trabajo e Inmigración, Madrid, 2008.

AAVV: Determinantes de la brecha salarial de género en España, Ministerio de Sanidad, Servicios Sociales e Igualdad, Madrid, 2012. 
El Papel de la Inspección de Trabajo y Seguridad Social...

AAVV (MERCADER UGUINA, J. dir.): Comentarios laborales de la Ley de Igualdad entre mujeres y hombres, Tirant lo Blanch, Valencia, 2007.

AAVV: Brecha salarial: causas e indicadores, Emakunde, Vitoria, 2012.

AAVV (Sanguineti Raymond, W. dir.): Propuestas para la igualdad de género en la negociación colectiva. Estudios a partir de la negociación colectiva en Castilla y León, Bomarzo, Madrid, 2011.

AAVV: Igualdad de trato entre hombres y mujeres en el ámbito laboral: la aportación de la Inspección de Trabajo y Seguridad Social, MTAS, Madrid, 1999.

AAVV: Primer Centenario de la Inspección de Trabajo y Seguridad Social, Publicación Conmemorativa, MTAS, Madrid, 2006.

AMUEDO-DORANTES, C. y S. DE LA RICA: «The Impact of Gender Segregation on Male-Female Wage Differentials: Evidence from Matched Employer-Employee Data for Spain» IZA Discussion Paper No. 1742, 2005.

BARTH, ERLING, BRATSBERG, BERNT, HAEGELAND, TORBJORN y RAAUM, ODDBJORN,: "Performance Pay and Within-Firm Wage Inequality» (2009). IZA Discussion Paper No. 4137. Disponible en SSRN: http://ssrn.com/abstract=1395244

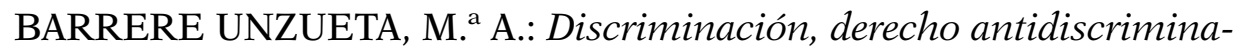
torio y acción positiva a favor de las mujeres, Civitas, Madrid, 1997.

CABEZA PEREIRO, J.: «La discriminación retributiva por razón de sexo como paradigma de discriminación sistémica», en Ian Harremanak/25 (2012).

CEBRIÁN, I. y MORENO, G.: «La situación de las mujeres en el mercado de trabajo español: desajustes y retos», Revista de Economía Industrial n. ${ }^{\circ}$ 367, 2008.

ENCARNA BODELÓN y NOELIA IGAREDA: Los planes de igualdad en tiempos de crisis. Problemas de aplicación y carencias conceptuales, Dykinson, Madrid, 2013.

FERNÁNDEZ LÓPEZ, M. ${ }^{a}$ F.: «La igualdad y la discriminación en la jurisprudencia constitucional», en AAVV (M. R. Alarcón Caracuel, coord..) Constitución y Derecho del Trabajo: 1981, 1991 (Análisis de diez años de jurisprudencia constitucional, Marcial Pons, Barcelona, 1992. 
FIGUERUELO BURRIEZA, A. y IBÁÑEZ MARTÍNEZ, M. L.: El reto de la efectiva igualdad de oportunidades, Comares, Granada, 2006.

GIMÉNEZ GLUCK, D.: Una manifestación polémica del principio de igualdad: acciones positivas moderadas y medidas de discriminación inversa, Tirant lo Blanch, Valencia, 1999.

GÓMEZ SÁNCHEZ, Y.: Constitucionalismo multinivel: derechos fundamentales, Sanz y Torres, Madrid, 2011.

LOUSADA AROCHENA, J. F.: El principio de transversalidad de la dimensión de género, MTAS, Madrid, 2007.

MARTÍN VIDA, M. ${ }^{a}$ A.: Evolución histórica del principio de igualdad y paradojas de la exclusión, Universidad de Granada, 2004.

MARTÍN VALVERDE, A., RODRÍGUEZ-SAÑUDO GUTIÉRREZ, F. y GARCÍA MURCIA, J.: Derecho del Trabajo, Tecnos, Madrid, 2002.

NOGUEIRA GUASTAVINO, M.: «El principio de igualdad y no discriminación en las relaciones laborales: perspectiva constitucional reciente», en Ian Harremanak/25 (2012).

RODRÍGUEZ-PIÑERO, M.: Igualdad y no discriminación en el empleo, en Derecho y Conocimiento, vol. 1.

- «El principio de igualdad y el Derecho del Trabajo», en El principio de igualdad en la Constitución española, Ministerio de Justicia, Secretaría General Técnica, Centro de Publicaciones, vol. II, Madrid, 1991.

- «La igualdad de remuneración entre trabajadores y trabajadoras y el artículo 119 del Tratado de Roma», en $R L, \mathrm{n}^{\circ}$ 1, 1986.

PÉREZ DEL RÍO, T.: Discriminación por razón de género y negociación colectiva, disponible en emakunde.euskadi.net/072-publicac/es/ contenidos/información/pu-jornadas

- La discriminación por razón de género en el empleo y las condiciones de trabajo, Carl, Sevilla, 2009.

PÉREZ LUÑO, A. E.: Derechos humanos, Estado de Derecho y Constitución, Tecnos, Madrid, 1986

- Dimensiones de la igualdad, Dykinson, Madrid, 2007.

QUINTANILLA NAVARRO, B.: Discriminación retributiva. Diferencias salariales por razón de sexo, Marcial Pons, Madrid, 1996. 
REY MARTÍNEZ, F.: «El principio de igualdad y el derecho fundamental a no ser discriminado por razón de sexo», en Diario La Ley, 2000, D-27, tomo 1.

SÁEZ LARA, C.: Mujeres y mercado de trabajo, CES, Madrid, 1994.

SALDAÑA VALDERAS, E.: Discriminación retributiva en función del género: un análisis técnico y jurídico, Megablum, Sevilla, 2004.

SIERRA HERNAIZ, E.: Acción positiva y empleo de la mujer, CES, Madrid, 1996.

SIMÓN, HIPÓLITO J.; LOBO, Raúl Ramos y SANROMÁ, Esteban: «Evolución de las diferencias salariales por razón de sexo,» Revista de Economía Aplicada, Universidad de Zaragoza, Departamento de Estructura Económica y Economía Publica, vol. 16(3), 2008, pags. 37-68.

VALDÉS DAL-RE, F.: Igualdad de género y relaciones laborales: entre la ley y la negociación colectiva, Reus, Madrid, 2010 
